\title{
Visión de la economía salvadoreña desde la perspectiva de la equidad de género
}

\author{
Julia Evelin Martínez
}

\section{Introducción}

Del 5 al 9 de junio de este año, se llevó a cabo, en la ciudad de Nueva York, el período extraordinario de sesiones de la Asamblea General de Naciones Unidas bajo el tema "La mujer en el año 2000: igualdad entre los géneros, desarrollo y paz en el siglo XXI", más conocido simplemente como la conferencia de Beijing +5 . El objetivo de la conferencia lo constituyó la revisión y actualización de los progresos alcanzados tras la aplicación de la Plataforma de acción de la Cuarta Conferencia de la Mujer, celebrada en Beijing, en 1995.

La delegación salvadoreña, encabezada por Lourdes de Flores, en su discurso ante la Asamblea General de la ONU, planteó como los principales logros de El Salvador - en los cinco años transcurridos desde la IV Conferencia de la Mujer- la creación del Instituto Salvadoreño de Desarrollo de la Mujer (ISDEMU), la aprobación de la Política Nacional de la Mujer y la aprobación e 
implementación de un marco legal e institucional, que previene y sanciona las diversas formas de violencia contra las mujeres'.

Como es usual en este tipo de reuniones mundiales, los debates más críticos y controversiales se centraron en los temas relacionados con el derecho al ejercicio libre de la maternidad; en el reconocimiento de los derechos sexuales de las mujeres y en el derecho a la no discriminación por orientación sexual, y menos en la discusión de cómo hacer realidad las bases materiales que aseguran los derechos económicos y sociales de las mujeres.

De igual forma, y como ya es una costumbre, los periódicos más influyentes de nuestro país se abstuvieron de brindar una cobertura integral de la problemática involucrada en la conferencia, y se limitaron a reseñar notas relacionadas con la "lucha por la defensa de los valores familiares"2, que se habría librado en las reuniones oficiales y no oficiales en Nueva York, y que amenazarían -en su opinión- con "vulnerar los valores morales que comparten la mayoría de salvadoreños"3. Esto refiriéndose a las supuestas implicaciones que el reconocimiento de derechos sexuales a las mujeres tendría para la moralidad pública de nuestro país y del mundo, y que en la perspectiva de los medios de comunicación habrían planteado en el seno de la ONU una especie de crucial batalla entre las fuerzas del bien y del mal4.

El período de extraordinarios de sesiones de la ONU concluyó con la suscripción de un Documento para el fortalecimiento de acciones e iniciativas para la implementación de la Declaración y la Plataforma de acción, aprobada cinco años antes en Beijing. Dicha declaración reconoce que, no obstante han ocurrido progresos en cada una de las doce áreas que conforman la Plataforma de acción, persisten obstáculos que impiden todavía la plena realización de los derechos de las mujeres, particularmente en las áreas de violencia de género, participación de las mujeres en la toma de decisiones, acceso a servicios de educación y de salud (incluyendo salud reproductiva y sexual), acceso a recursos productivos, y el apoyo a las mujeres ante situaciones de desastres naturales, sociales o políticos ${ }^{5}$.

Finalizada Beijing +5 y una vez que la delegación salvadoreña retornó al país con el compromiso de "una vez más cumplir con los acuerdos suscritos por el gobierno en Beijing hace cinco años", se plantea la necesidad de realizar una revisión retrospectiva de los avances ocurridos en nuestro país, de cara a los compromisos suscritos a favor de la equidad de género en las 12 áreas de la Plataforma de acción de la IV Conferencia de la Mujer, con el objetivo de determinar el grado de compromiso real que existe en nuestro país en torno a la equidad, más allá de los discursos y de las declaraciones de buenas intenciones oficiales al respecto.

En este artículo se propone realizar una reflexión sobre las tendencias de la equidad de género en El salvador desde uno de los ámbitos menos conocidos y menos debatidos dentro de las discu-

1. "Primera Dama destaca el papel de la mujer", El Diario de Hoy, 9 de junio de 2000, p. 15.

2. "Una reunión controversial en Nueva York", La Prensa Gráfica, 12 de junio de 2000, p. 89.

3. "Férrea lucha por valores en Naciones Unidas", El Diario de Hoy, 10 de junio de 2000, p. 21.

4. A propósito de esta cobertura de prensa, un miembro del personal de articulistas de El Diario de Hoy escribió, sobre la reunión de Beijing +5 , que "este foro es mucho más que el empeño de unos pocos por instaurar a la fuerza la perspectiva de género en el análisis social, o para lograr una "equiparación" entre los hombres y las mujeres... Me parece que es un escaparate en el que podemos ver la lucha entre dos concepciones del ser humano: la de aquellos que saben que los hombres y las mujeres son seres trascendentes y que dependen de su libertad para irse perfeccionando con su conducta, y la de quienes tienen una visión plana, sin referencia a la dignidad intrínseca que tiene el ser humano por estar dotado de libertad. Los primeros sabemos que si bien los hombres y las mujeres son distintos entre sí, tienen igual dignidad constitutiva, y unas peculiaridades al margen de las cuales no se puede encontrar la felicidad; los segundos piensan que la distinción hombre-mujer es artificial y que la felicidad se encuentra por la ausencia de condicionamientos, incluso los condicionamientos que impone a los seres humanos la naturaleza misma". Ver Carlos Mayora Ré, "El Cairo, Beijing y Usted", El Diario de Hoy, 10 de junio de 2000, p. 19.

5. Ver Naciones Unidas, "Further Actions and Initiatives to Implement the Beijing Declaration and Platform for Action", documento final adoptado por la plenaria de la sesión especial de la Asamblea General (inédito), 10 de junio de 2000.

6. "Primera dama ante la ONU: crearán política para la Mujer", El Diario de Hoy, 8 de junio de 2000, p. 61. 
siones oficiales y no oficiales sobre avances y obstáculos de equidad de género: el ámbito de la participación de la mujer en la economía. El énfasis en la dimensión económica de la equidad, que se propone en este artículo, no debe interpretarse - de ninguna forma - como el abandono de otras dimensiones que configuran la situación de subordinación, exclusión y marginación de las mujeres en la sociedad salvadoreña, ni tampoco como una pretensión de otorgarle a la dimensión económica el status de condición de "última instancia", que explicaría o podría solucionar la desigualdad de género en las sociedades.

Lejos de ello, el contenido de este artículo se centra en las tendencias de desigualdad entre hombres y mujeres en la economía por tres razones fundamentales. En primer lugar, porque el ámbito de la participación de las mujeres en la economía ha tendido a estudiarse menos en relación con la participación de las mujeres en otras ámbitos de la vida social, tales como la pobreza, la salud, la violencia, la educación y las relaciones familiares. Por consiguiente, actualmente constituye una de las áreas de seguimiento y vigilancia de la Plataforma de acción de la IV Conferencia de la Mujer menos estudiadas y menos documentadas.

En segundo lugar, porque en el campo de la investigación y el análisis académico que se promueve desde la universidad, la preocupación por el tema de mujer y economía ha sido ignórado y/o descalificado como relevante para el estudio de las condiciones coyunturales y estructurales de la economía salvadoreña. Esta actitud ha sido el resultado de la aplicación de una visión reduccionista y agregada sobre lo económico, que ha privado $-y$ sigue privando- en la formación de los y las profesionales de las ciencias económicas, la cual ha respondido fundamentalmente a la pretensión de las personas e instituciones responsables de este análisis acerca de una supuesta "neutralidad de género" que tienen los supuestos de la teoría econó- mica y las medidas de política económica, principalmente de la política macroeconómica. En tal sentido, se ha considerado hasta ahora que el análisis de las variables macroeconómicas se encuentra a un nivel tan agregado y tan alejado de los agentes económicos, que sería irrelevante y/o inoficioso pretender introducir —en este análisis- la desigual distribución del poder económico entre hombres y mujeres o los distintos roles y comportamientos económicos entre los hombres y las mujeres frente a la política económica. En consecuencia, es necesario comenzar a generar -desde el terreno académico- una reflexión seria sobre estos tópicos, de cara a la urgente tarea de actualización y aplicación de la teoría económica a la realidad nacional.

En tercer lugar, porque en la visión del Desarrollo Humano Sostenible y el marco conceptual y analítico que a él çorresponde, se han mostrado las insuficiencias que los parámetros del crecimiento económico, estabilidad macroeconómica y acumulación de capital tienen para observar el panorama completo del desenvolvimiento económico de una sociedad, si éstos no consideran de manera explícita una preocupación por el tema de la equidad. Entendida ésta tanto como equidad entre las presentes y las futuras generaciones, como equidad entre grupos $y$ segmentos de la población, y como equidad en las aspiraciones y las oportunidades de desarrollo entre hombres y mujeres.

En este contexto, el presente artículo tiene como objetivo realizar una contribución al debate académico y político en torno al tema del funcionamiento y de las tendencias de la economía salvadoreña desde la perspectiva de la participación de los hombres y las mujeres, con miras a identificar los principales obstáculos que continúan bloqueando el funcionamiento de una economía más equitativa, más sustentable y más justa, y cuya eliminación define uno de los contenidos fundamen- 


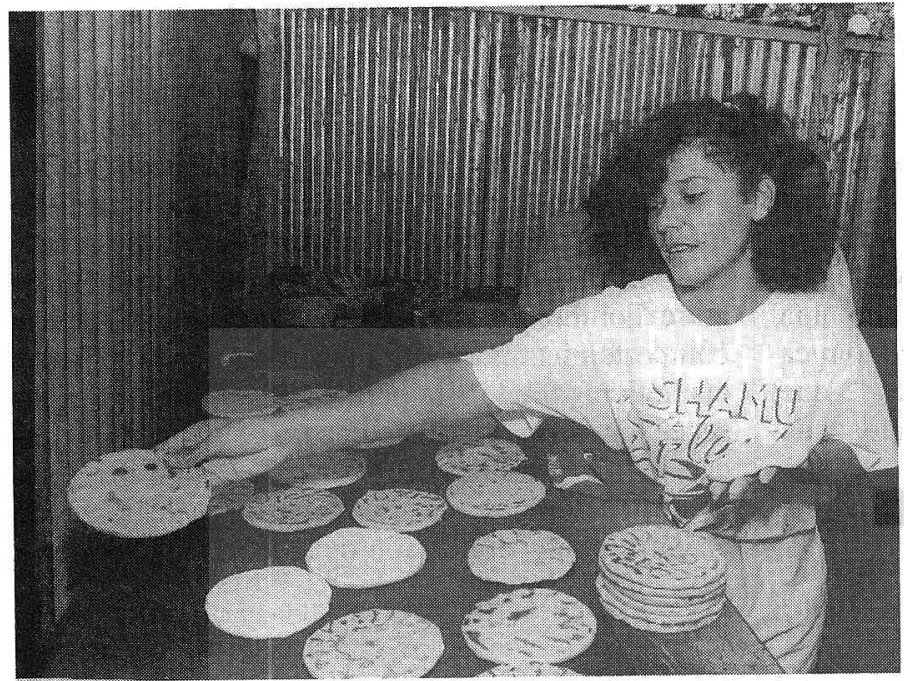

res. Más de 500000 participantes convirtieron este evento en la conferencia más grande en la historia de las Naciones Unidas: 5000 delegadas provenientes de 189 países; 4000 mujeres representantes de organismos no gubernamentales y 3200 periodistas. Asimismo, se organizó un Foro de organismos no gubernamentales que sesionó de forma pàralela a la Conferencia de la ONU y al cual asistieron 27000 mujeres ${ }^{\sharp}$.

La plataforma de acción aprobada por unanimidad en Beijig, en 1995, definió un conjunto de objetivos estratégicos y de medidas urgentes, que los países se comprometieron a adoptar a más tardar en el año 2000 para elimi-

tales de la agenda pendiente de la equidad de género en El Salvador.

El artículo está estructurado en tres partes. En la primera parte se exponen los antecedentes de Beijin +5 , específicamente los compromisos asumidos en el área mujer y economía. A continuación se efectúa una revisión de los avances de esos compromisos desde la perspectiva del objetivo de crear una economía con mayor equidad de género. Finalmente, en la tercera parte se realiza un balance de los avances y obstáculos que se derivan del examen del estado actual de la equidad de género de la economía, el cual finaliza con una reflexión general acerca de los principales retos que se plantean en esta área?.

1. Los antecedentes: el área mujer y economía dentro de la Plataforma de acción de la IV Conferencia de la Mujer y la declaración final de Beijing +5

La IV Conferencia Mundial sobre la Mujer, llevada a cabo en Beijing en septiembre de 1995, representó un hito en la historia por la igualdad y la vigencia de los derechos humanos de las muje- nar los obstáculos al desarrollo de las mujeres. A diferencia de las conferencias anteriores, las estrategias y los compromisos aprobados en Beijing definieron un mayor nivel de compromiso y alcance de los acuerdos; en esa misma medida, los gobiernos firmantes se comprometieron a incorporar la perspectiva de género en las políticas y los programas gubernamentales. Asimismo, en la Plataforma de acción de la conferencia se incorporaron acuerdos para el seguimiento de la conferencia y para la implementación de los compromisos adquiridos.

Doce problemas que obstaculizan el "empoderamiento" de las mujeres a nivel mundial trató de enfrentar la Plataforma de acción de Beijing, mediante la definición de una agenda global de acción de 54 objetivos específicos y 535 medidas, cada una de las cuales comprende una serie de actividades y tareas a ser adoptadas por los gobiernos nacionales, organizaciones no gubernamentales, organismos intemacionales, entre otros actores.

La diversidad de medidas, actividades y tareas que encierra la Plataforma de Beijing es un reflejo

7. Las estadísticas que se presentan en todos los cuadros de este artículo contienen información relacionada con la república de El Salvador.

8. Ver Fundación Friedrich Ebert, "Políticas de promoción de la mujer después de Pekin: la plataforma de acción de la Cuarta Conferencia Mundial sobre la mujer", Alemania, 1997.

9. El término "empoderamiento" constituye el término crucial que le da coherencia conceptual a la Plataforma de acción de la IV Conferencia de la mujer. Este término es una traducción de la palabra inglesa empowerment, y trata de describir una situación de goce pleno de los derechos de la mujer, en todas las esferas de la vida y contra cualquier uso de la fuerza basada en el género. 
del complejo proceso de negociación que se llevó a cabo entre los organismos de Naciones Unidas, los gobiernos nacionales y las organizaciones no gubernamentales. Sin embargo, lo importante por destacar es el consenso mundial alcanzado a nivel mundial en tomo a las 12 áreas consideradas más críticas para el ejercicio pleno de los derechos de las mujeres, que fueron identificadas como las siguientes: $(a)$ mujer y pobreza, $(b)$ educación y capacitación de las mujeres, $(c)$ la mujer y la salud; $(d)$ la violencia contra la mujer, $(e)$ la mujer y los conflictos armados, $(f)$ la mujer y la economía, $(g)$ mujeres en el ejercicio del poder y en la adopción de decisiones, $(h)$ mecanismos institucionales para la promoción de la mujer, (i) los derechos humanos de las mujeres, $(j)$ la mujer y los medios de comunicación social, $(k)$ la mujer y el medio ambiente, y $(l)$ la situación de las niñas y las adolescentes.

En el área mujer y economía, la Plataforma de acción define seis objetivos estratégicos:

$1^{2}$. Promover la independencia y los derechos económicos de la mujer, incluidos el acceso al empleo, a condiciones de trabajo apropiadas y al control de los recursos económicos.

$2^{2}$ Facilitar el acceso de la mujer, en condiciones de igualdad a los recursos, el empleo, los mercados y el comercio.

$3^{2}$ Proporcionar a la mujer servicios comerciales, capacitación, y acceso a los mercaḍos, información y tecnología, particularmente a las mujeres de bajos ingresos.

$4^{2}$ Reforzar la capacidad económica y las redes comerciales de las mujeres.

$5^{2}$ Eliminar la segregación en el trabajo y todas las formas de discriminación en el empleo.

$6^{2}$ Fomentar la armonización de las responsabilidades de las mujeres y los hombres en lo que respecta al trabajo y a la familia.

El logro de estos objetivos estratégicos presupone la adopción de medidas concretas por parte de los gobiernos nacionales, orientadas a generar las condiciones jurídicas, institucionales y de política económica que hagan posible la participación igualitaria de las mujeres en el quehacer económico. Se plantea, por ejemplo, la necesidad de que los gobiernos apoyen la participación igualitaria en la definición de los marcos institucionales y de política pública que tengan impacto en la actividad económica y, además, promuevan el acceso de las mujeres a las posiciones claves, desde el punto de vista de las decisiones de política económica. Asimismo, los gobiernos deberían evaluar el impacto específico de género de las instituciones, las relaciones comerciales, los flujos de bienes, los servicios y de capital, y proceder a incorporar reformas acorde al espíritu de la Plataforma de acción.

Cinco años después, la Declaración Final de Beijing +5 destaca avances en el tema de mujer y economía, principalmente en términos de una mayor participación de las mujeres en el mercado laboral, y, por tanto, de una autonomía económica de las mujeres. Se reconoció que algunos gobiernos han implementado una variedad de medidas dirigidas a promover los derechos económicos y sociales de las mujeres, a equiparar el acceso y control sobre los recursos económicos y hacia la equidad en el empleo ${ }^{\prime \prime}$.

Esta declaración también reconoce como avances las decisiones de algunos gobiernos de ratificar algunos convenios internacionales sobre trabajo, que protegen los derechos de las mujeres trabajadoras, y la promulgación y/o fortalecimiento de la legislación existente en sus países para hacerla compatible con los convenios internacionales ratificados. Por otra parte, se consideran señales positivas a favor de la igualdad de las mujeres la aprobación —en algunos países- de la legislación que sanciona prácticas discriminatorias y conductas abusivas contra las mujeres en los lugares de trabajo, así como la aprobación de regulaciones para prevenir condiciones insalubres de trabajo y del establecimiento de mecanismos financiados con fondos públicos para promover el rol de las mujeres en la educación, la capacitación y las actividades empresariales, incluyendo formación de habilidades científicas y técnicas y la participación de las mujeres en la toma de decisiones".

\footnotetext{
10. Naciones Unidas, "Further Actions and Initiatives to Implement the Beijing Declaration and the Platform for Action". Documento final adoptado por la plenaria de la 23" sesión especial de la Asamblea General, 2000.

11. Ibidem.
} 
Por el lado de los obstáculos a la equidad de género, que persisten en el ámbito de la economía, Beijing +5 enfatiza los que se citan a continuación ${ }^{12}$.

- La falta de reconocimiento de la importancia de la perspectiva de género en el desarrollo de la política macroeconómica.

- La existencia de mujeres que trabajan en las áreas rurales y en la economía informal como productoras de subsistencia y en el sector de los servicios, con bajos niveles de ingresos y con baja cobertura de seguridad social y protección en el trabajo.

- Muchas mujeres en el sector formal con la misma experiencia y habilidades que los hombres, todavía enfrentan una brecha salarial de género que las mantiene rezagadas, en términos de ingreso y de posibilidades de movilidad laboral.

- No se ha realizado aún totalmente el principio de un salario igual por un trabajo igual o por trabajo de igual valor.

- Persistencia de la discriminación contra las mujeres en la contratación y los ascensos laborales, en relación con la maternidad, incluyendo la realización directa de pruebas de embarazo y la existencia de acoso sexual en los lugares de trabajo.

- En la legislación de algunos países no se encuentran reconocidos aún los derechos de la mujeres para acceder a la propiedad de la tierra y otros tipos de propiedad, incluyendo los derechos de herencia.

- En muchos casos, el progreso en muchas profesiones es más difícil para las mujeres, debido a la falta de estructuras y de medidas que tomen en consideración la maternidad y las responsabilidades familiares.

- En algunos casos, se constata la persistencia de estereotipos de género, que ha llevado a la desvalorización del estatus de los trabajadores como padres y que no estimulan a los hombres a reconciliar sus responsabilidades profesionales y familiares; situación que es agravada por la falta de políticas de familia que sean favorables a la reorganización del trabajo familiar.
- La combinación de trabajo remunerado y de trabajo no remunerado para el cuidado de la familia, la realización de labores domésticas y para la comunidad aún representa una desproporcionada carga que debe ser asumida por las mujeres, que contrasta con la insignificante contribución en las tareas y responsabilidades de los hombres en este ámbito.

De cara al futuro, los países firmantes de la Declaración final de Beijing +5 , reunidos en Nueva York, se comprometieron a adoptar las siguientes medidas para fortalecer las acciones encaminadas a un mayor empoderamiento de las mujeres en esta área:

(a) Asegurar que la legislación nacional y los procesos de reformas administrativas, incluyendo aquellos relacionados con la reforma de tierras, descentralización y reorientación de la economía, estén vinculados al fortalecimiento de los derechos de las mujeres, particularmente de las mujeres rurales y de las que viven en situación de pobreza; y adoptar medidas para promover e implementar aquellos derechos que de manera directa garanticen acceso y control igualitario sobre los recursos económicos, incluyendo la propiedad de la tierra, los derechos de propiedad, derechos de herencia, crédito y programas tradicionales de ahorro y crédito, tales como bancos de la mujer y cooperativas.

(b) Incorporar la perspectiva de género como un componente principal de la política macroeconómica y de la política social, así como de los programas nacionales de desarrollo.

(c) Incorporar la perspectiva de género al diseño, el desarrollo, la adopción y ejecución de todo el proceso presupuestario como un instrumento para promover una equitativa, efectiva y apropiada asignación de los recursos nacionales y para el establecimiento de asignaciones presupuestarias, que apuntalen la equidad de género y el desarrollo de programas en los cuales se busque incrementar el empoderamiento de las mujeres. Asimismo, los gobiernos se comprometen a desarrollar los instrumentos analíticos y metodológicos y los mecanismos para vigilar y evaluar los resultados.

(d) Emprender políticas socioeconómicas que promuevan el desarrollo sostenible $y$ apoyen $y$

12. Ibidem. 
aseguren los programas de erradicación de la pobreza, dirigidos especialmente a mujeres, y que provean, entre otras cosas, capacitación para el desarrollo de habilidades, igualdad en el acceso y control de recursos financieros, crédito (incluyendo microcréditos), información, tecnología e igualdad en el acceso a los mercados en beneficio de las mujeres de todas las edades, en particular de aquellas que viven en situación de pobreza y de marginación: mujeres rurales, mujeres indígenas y mujeres jefes de hogar.

(e) Crear y asegurar igualdad en el acceso a los sistemas de protección social, tomando en cuenta las necesidades específicas de todas las mujeres que viven en situación de pobreza, los cambios demográficos y los cambios en la sociedad, a efecto de proteger a las mujeres contra la incertidumbre y los cambios en las condiciones de trabajo, derivadas de la globalización de la economía, y procurando garantizar que las nuevas, flexibles y emergentes formas de trabajo estén adecuadamente cubiertas por los sistemas de seguridad social.

(f) Facilitar el empleo para mujeres, entre otros cosas, por medio de una adecuada protección social, simplificación de procedimientos administrativos, eliminación de obstáculos fiscales, en donde estas medidas sean apropiadas. Otras medidas que deben ser consideradas por los gobiernos deberían ser la promoción del acceso de las mujeres a capital de riesgo, proyectos de créditos y de microcréditos, y facilitar la creación de micro, pequeñas y medianas empresas de mujeres.

(g) Proveer a las oficinas nacionales de estadísticas de apoyo institucional y financiero para recolectar, compilar y divulgar datos estadísticos desagregados por sexo, edad y otras variables, en formatos que sean accesibles para el público y los responsables de definir la política económica, y para posibilitar, entre otras cosas, la realización de análisis de género, la vigilancia y las evaluaciones de impacto, y dar soporte al desarrollo de nuevas estadísticas e indicadores, especialmente en aquellas áreas en las cuales la información es particularmente escasa.

(h) Desarrollar la capacidad nacional para asumir un compromiso con la elaboración de políticas orientadas a la equidad de género y hacia la realización de investigaciones y estudios de impacto con perspectiva de género por parte de las universidades y los institutos de investigación y de for-

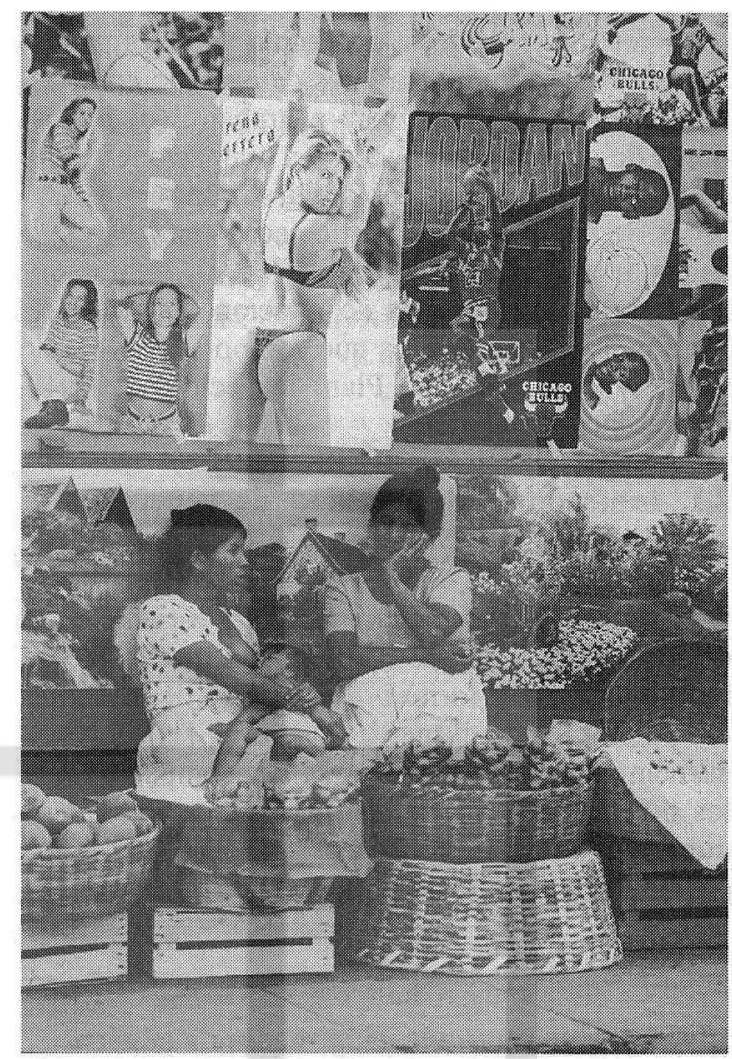

mación, con miras a la creación de un marco de conocimientos especializados sobre el tema, que sirva de base para el proceso de formulación de políticas públicas con enfoque de género.

\section{Evolución de los indicadores de equidad de género de la economía salvadoreña}

En este apartado se recogen los principales resultados que arrojan los indicadores de seguimiento y evaluación del área mujer y economía en EI Salvador, con el objetivo de establecer un punto de referencia para determinar los retos futuros que se plantean en nuestro país para promover una mayor equidad de género en el ámbito económico.

La construcción de la mayor parte de los indicadores que se presentan se ha realizado con base en la información disponible en el país y siguiendo la metodología propuesta por la CEPAL (1999) para el seguimiento de la IV Conferencia de la Mujer en el área mujer y economía. Los indicadores se han agrupado en cinco grandes categorías: $(a)$ indicadores de equidad en el acceso al mercado laboral; $(b)$ indicadores de equidad en 
el sector informal de la economía y en las pequeñas empresas; $(c)$ indicadores de equidad en el acceso a la capacitación para el trabajo; (d) indicadores de equidad en el acceso a ocupaciones especializadas y a los puestos de dirección; $(e)$ indicadores de equidad en la participación en las actividades reproductivas realizadas en el ámbito doméstico. Cada categoría se relaciona con uno de los objetivos estratégicos que componen el área de mujer y economía del Plan de acción de la IV Conferencia de Beijing.

\subsection{Indicadores de equidad de género en el mercado laboral}

Este grupo de indicadores están orientados a determinar la igualdad o diferencia que existe en las condiciones y formas de inserción de las mujeres y hombres en el mercado laboral, las cuales se derivan principalmente del análisis comparativo de los niveles salariales y de su participación en los diferentes sectores económicos y categorías ocupacionales.

\section{Cuadro 1}

Índice de remuneración media de género de los salarios nacionales (urbano y rural nacional)

\begin{tabular}{ll}
\hline Año & IRMG \\
\hline 1996 & 67.24 \\
1997 & 73.28 \\
1998 & 71.06 \\
Promedio & 70.52 \\
\hline
\end{tabular}

IRMG= salarios promedios femeninos entre salarios promedios masculinos por 100.

Fuente: Elaboración propia sobre la base de datos de las Encuestas de Hogares de Propósitos Múltiples.

El índice de rernuneración media de género (IRMG) mide los salarios promedios de las mujeres como proporción de los salarios medios de los hombres, vigentes a nivel nacional, en un período determinado. La evolución del IRMG (Cuadro 1), en el período 1996-1995, muestra una tendencia al

\section{Cuadro 2}

Índice de remuneración media de género de salarios nacionales con corrección educacional

\begin{tabular}{lccc}
\hline $\begin{array}{l}\text { Años de estudio } \\
\text { aprobados }\end{array}$ & $\begin{array}{c}\text { IRGM } \\
1996\end{array}$ & $\begin{array}{c}\text { IRGM } \\
1997\end{array}$ & $\begin{array}{c}\text { IRGM } \\
1998\end{array}$ \\
\hline Total & 67.24 & 73.28 & 71.06 \\
Ninguno & 66.64 & 81.91 & 103.0 \\
$1-3$ & 63.47 & 71.56 & 75.00 \\
$4-6$ & 61.88 & 65.36 & 66.00 \\
$7-9$ & 60.09 & 75.44 & 74.00 \\
$10-12$ & 79.76 & 81.32 & 76.00 \\
13 y más & 68.58 & 66.35 & 76.00 \\
\hline
\end{tabular}

Fuente: Elaboración propia sobre la base de datos de las Encuestas de Hogares de Propósitos Múltiples, DIGESTYC.

alza, ya que de 72.6 , en 1996 , pasa a 71.0 , en 1998. Y, en promedio, para los tres años considerados, los salarios de las mujeres a nivel nacional representaron el 70.52 por ciento de los salarios de los hombres. Dicho en términos más comprensibles, los salarios promedios de las mujeres fueron 29.63 por ciento menores a los salarios de los hombres, en el período considerado.

Ya que usualmente las brechas salariales entre mujeres y hombres tienden a atribuirse a las diferencias en la escolaridad y/o capacitación para el trabajo entre ambos sexos, es necesario considerar los resultados del índice de remuneración media de género bajo la consideración de las diferencias educacionales, con el objetivo de obtener una perspectiva más cercana al fenómeno de las diferencias salariales entre mujeres y hombres. El Cuadro 2 muestra los resultados de esta comparación salarial cuando se introduce la variable educacional y —según éstos- las brechas salariales entre mujeres y hombres se mantienen para todos los niveles de escolaridad promedio, es decir, independientemente del mayor o menor nivel educativo alcanzado por mujeres o hombres. Esto es, se constata la existencia de una diferencia salarial que tiene a la base las diferencias de género y no las diferencias educacionales. En efecto, diversos estudios sobre el comportamiento de los salarios en América Latina ${ }^{13}$

13. Irma Arriagada, "Realidades y mitos del trabajo fernenino urbano en América Latina", CEPAL, Santiago de Chile, agosto, 1997; George Psacharopoulos y Zafiris Tzannatos, Women's Employment and Pay in Latin America. Overview and Methodology, Washington, D.C., World Bank, 1992. 
concluyen, a partir del análisis de las trayectorias laborales de hombres y mujeres con la misma calificación, que aun cuando partan del mismo nivel de ingresos, la brecha salarial entre ambos tiende a incrementarse, en la medida que los hombres tienden a escalar rápidamente posiciones mejor remuneradas y con mayor prestigio y poder, en tanto que las mujeres permanecen en los mismos puestos, por lo que "una porción muy significativa del diferencial de ingresos entre hombres y mujeres, que no queda explicada, es atribuible a la discriminación basada en el género"14.

Respecto a los niveles salariales de mujeres y hombres en el mercado laboral salvadoreño, es importante reparar en las significativas diferencias que se presentan entre los salarios del sector público y del sector privado (Cuadro 3).

\section{Cuadro 3}

\section{Índice de remuneración media de género de los salarios}

en el sector público y privado

\begin{tabular}{lcc}
\hline Año & IRMG Sector público & IRGM Sector privado \\
\hline 1996 & 109.4 & 62.04 \\
1997 & 101.4 & 62.00 \\
1998 & 105.0 & 65.09 \\
Promedio & 105.43 & 63.04 \\
\hline
\end{tabular}

IRMG= índice de remuneración media de género.

Fuentes: Dirección General de Estadística y Censos, Ministerio de Economía. Encuestas de Hogares de Propósitos Múltiples.

La tendencia de los salarios, en el sector público, en el período 1996-1998, muestra un comportamiento a favor de la equidad de género, inclusive se constata una tendencia de los salarios femeninos a ser levemente superiores a los salarios masculinos, probablemente por las disposiciones contenidas en la Ley del presupuesto, que determinan exante el salario que corresponde a la plaza que será objeto de contratación en el sector público, y que se mantiene en vigor independientemente que quien ocupe la plaza sea hombre o mujer. La tendencia opuesta parece predominar en las contrataciones del sector privado: en promedio, durante los tres años considerados, los salarios de las mujeres se mantuvieron por debajo de los salarios masculinos, incluso más abajo del índice de remuneración media de género IPGM a nivel nacional. Sin embargo, pese a esta mayor equidad salarial que caracteriza al sector público, debe tomarse en consideración el hecho de que el sector público continúa siendo un sector predominante masculino, ya que de acuerdo con los datos de la Encuesta de Hogares de Propósitos Múltiples de 1998, del total de personas ocupadas en el sector público, el 65.4 por ciento son hombres, quienes proporcionalmente tienden a ocupar los puestos de mayor responsabilidad y poder en la toma de decisiones.

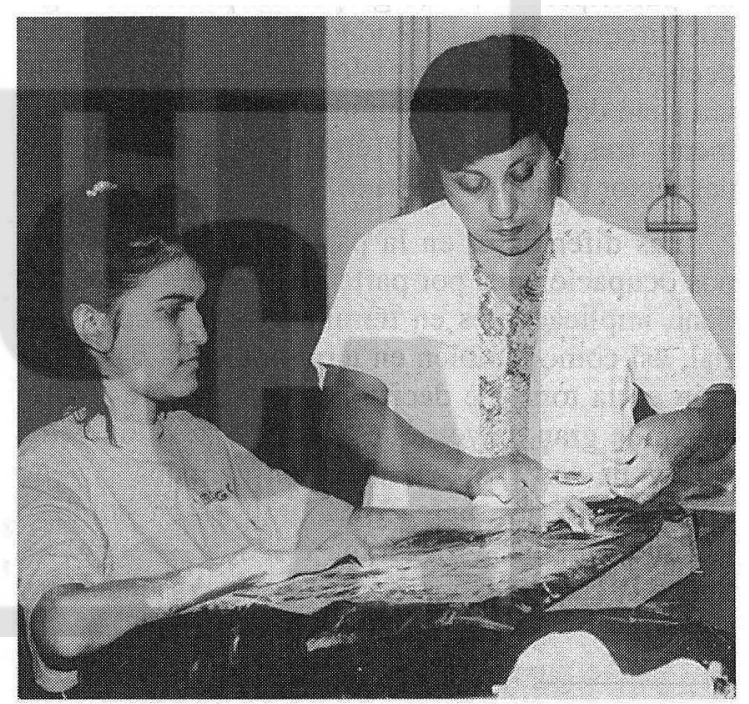

14. Irma Arriagada, "Realidades y mitos del trabajo femenino urbano en América Latina", CEPAL, agosto, 1997, p. 15. 


\section{Cuadro 4}

Participación de las mujeres en los diferentes grupos ocupacionales como proporción del total de ocupados en cada grupo

\begin{tabular}{l|c|c|c}
\hline Grupo ocupacional & $\begin{array}{c}\text { Porcentaje de mujeres } \\
(1996)\end{array}$ & $\begin{array}{c}\text { Porcentaje de mujeres } \\
(1997)\end{array}$ & $\begin{array}{c}\text { Porcentaje de mujeres } \\
(1998)\end{array}$ \\
\hline $\begin{array}{l}\text { Directores, funcionarios } \\
\text { Profesionales de alto nivel, }\end{array} \quad 28.9$ & 35.0 & 27.0 \\
$\quad$ científicos e intelectuales & 36.5 & 40.6 & 35.0 \\
Técnicos y profesionales & & & \\
$\quad$ de nivel medio & 6.4 & 46.0 & 52.0 \\
Fuerza Armada & 0.0 & 0.0 & 0.0 \\
Empleados de oficina & 59. & 64.0 & 62.0 \\
Comerciantes y trabajadores & & 69.0 & 66.0 \\
$\quad$ de los servicios & 69.3 & 4.4 & 5.0 \\
Trabajador agropecuario & 6.1 & 31.0 & 34.0 \\
$\quad$ y pesquero & 34.6 & 26.2 & 33.0 \\
Artesanos y operarios & 27.3 & 35.6 & 34.0 \\
Operadores de maquinaria & 33.7 & & \\
Trabajador no calificado & & & \\
\hline
\end{tabular}

Fuente: Encuesta de Hogares de Propósitos Múltiples, Ministerio de Economía.

En cuanto a la participación de mujeres y hombres en los diferentes grupos ocupacionales existentes en el mercado de trabajo, en el Cuadro 4 se evidencia una mayor participación de las mujeres en los grupos "empleados de oficina" y "trabajadores del comercio y de los servicios", y una menor participación en los grupos ocupacionales ligados directamente a la producción y/o a la toma de decisiones. Así, por ejemplo, las mujeres representan siete de cada diez empleados de oficina y solamente tres de cada diez directores o funcionarios del sector público o privado.

Las diferencias en la participación de los grupos ocupacionales por parte de hombres y mujeres tiene implicaciones en términos de la escala salarial, así como también en términos de la participación en la toma de decisiones: los hombres representan la gran mayoría de los directores, funcionarios y de los profesionales considerados de alto nivel dentro del mercado laboral, y son hombres los que deciden -en última instancia- sobre los temas de contrataciones, ascensos, capacitación y políticas laborales que rigen en el sector público y privado.

Los resultados anteriores están en concordancia con investigaciones previas sobre el tema de las diferencias de género en los grupos ocupacionales. Por ejemplo, Gammage ${ }^{15}$ concluye que las diferencias ocupacionales entre hombres y mujeres que tienen la misma escolaridad, se explica a partir de los preceptos socioculturales que rigen en estas sociedades, que determinan la división por género de las obligaciones en el hogar y en el trabajo. Refiere que estas diferencias tienden a perpetuarse, entre otros factores, en la medida que las empresas tienden a percibir que la inversión en la capacitación del personal femenino que puede retirarse en cualquier momento, tiene baja rentabilidad, y que las mujeres - aun con mayores niveles de escolaridad que los hombres- están menos preparadas para ocupar ciertas posiciones que requieren de una mayor calificación. De esta forma, el costo de excluir a una mujer del mercado laboral es menor $y$, por consiguiente, se le puede des-

15. Sara Gammage, "La Globalización y la composición de género del empleo en el sector manufacturero de América Latina", en Situación de las mujeres en Centroamérica: una evaluación en el umbral del siglo XXI, Isabel García (ed.), Fundación Género y Sociedad (GESO), 1999, p. 63. 
pedir con mayor facilidad. Así se consolida "la práctica de no invertir en la capacitación de mujeres, lo que a su vez perpetúa el hecho de relegarlas a empleos mal remunerados y de baja calificación"16.

Una revisión más detallada de las diferencias en la participación de hombres y mujeres en los grupos ocupacionales, evidencia más claramente la segmentación ocupacional de género que caracteriza al mercado laboral salvadoreño. Según las Encuestas del Mercado de Trabajo, realizadas por FUSADES entre 1993 y 1997, durante ese período, en el Área Metropolitana de San Salvador predominó la tendencia de las mujeres a insertarse laboralmente en actividades "típicamente femeninas" y de los hombres a laborar en actividades "típicamente masculinas".

De acuerdo con los datos de los Cuadros 5 y 6 , las opciones ocupacionales de las mujeres trabajadoras del Área Metropolitana de San Salvador continúan circunscribiendo a ocupaciones considera- das propias de mujeres: operarias de la industria de la confección, promotoras de ventas, empleadas de servicios de información al cliente, secretarias y digitadoras, trabajadoras y asistentes sociales de nivel medio, maestras de enseñanza primaria y preescolar, personal de enfermería, archiveros, bibliotecarios y afines, personal de restaurantes, auxiliares de contabilidad, y físicos, químicos y afines. En el otro extremo de esta tendencia, las mujeres continúan teniendo menos y/o ninguna opción para desempeñarse en ocupaciones tradicionalmente consideradas masculinas: personal directivo y de administración, profesionales de la informática, arquitectura e ingeniería, profesores universitarios, técnicos en ingeniería, optometristas, técnicos en biología, obreros de la construcción, mecánicos y ajustadores de máquinas y/o de equipos electrónicos, operarios de la industria metálica, de vidrio y cerámica; operarios de la industria de la madera y de papel; conductores de vehículos automotores, entre muchas otras ocupaciones.

\section{Cuadro 5}

Porcentaje de mujeres que trabajan en ocupaciones dominadas por hombres* (1993 y 1996) (En porcentajes)

\begin{tabular}{l|r|r}
\hline Ocupaciones dominadas por hombres & 1993 & 1996 \\
\hline Personal directivo de administración & 21.2 & 23.6 \\
Profesionales de informática & 19.8 & 22.5 \\
Arquitectos, ingenieros & 15.5 & 20.3 \\
Médicos & 12.5 & 44.4 \\
Profesores universitarios & 24.5 & 19.9 \\
Escritores, artistas y creativos & 22.1 & 27.6 \\
Técnicos en ciencias e ingeniería & 8.8 & 8.1 \\
Operadores de equipos ópticos y electrónicos & 6.59 & 3.0 \\
Técnicos en biología & 9.4 & 14.6 \\
Personal de servicios de protección y seguridad & 0.0 & $n . d$. \\
Jardineros & 0.0 & 0.4 \\
Obreros de la construcción & 0.1 & 0.0 \\
Pintores, limpiadores de fachadas & 0.0 & 0.0 \\
Mecánicos de obra de banco & 0.0 & 0.0 \\
Herreros y afines & 0.0 & 0.0 \\
Mecánicos y ajustadores de máquinas & 3.3 & 0.0 \\
Mecánicos y ajustadores de equipos electrónicos & 0.8 & 0.4 \\
Artesanos de la madera, tejidos, cuero y similares & 1.8 & 26.5 \\
Artesanos del tratamiento de la madera, ebanistas y afines & 0.0 & 12.7 \\
Artesanos de las pieles, cueros y calzado & 12.2 & 55.1 \\
Perforadores de pozos & 0.0 & 0.0 \\
Operarios de la industria metálica & 8.3 & 3.2 \\
Operarios de la industria de vidrio y cerámica & 1.1 & 3.2 \\
\hline
\end{tabular}

16. Sara Gammage, "La globalización...”, op. cit. 


\section{Cuadro 5 (continuación)}

\begin{tabular}{lrr}
\hline Ocupaciones dominadas por hombres & 1993 & 1996 \\
\hline Operarios de la industria de la madera y fabricación de papel & 0.0 & 0.0 \\
Operarios de la producción de energía y afines & 0.0 & 0.0 \\
Operarios líneas de ensamble & 0.0 & 100 \\
Operarios de la industria de minerales y metales & 0.5 & 7.6 \\
Operarios de la fabricación de productos de plástico & 14.7 & 48.3 \\
Operarios de fabricación de la madera & 4.1 & 19.2 \\
Operarios de imprenta, encuadenación y papel & 21.4 & 8.8 \\
Conductores de vehículos de motor & 0.0 & 0.0 \\
Operarios de maquinaria o máquinas móviles & 0.0 & 0.0 \\
Vendedores a domicilio y afines & 20.6 & 15.3 \\
Conserjes, lavadores y afines & 2.2 & 27.5 \\
Mensajeros, maleteros, porteros y afines & 6.3 & 0.6 \\
Peones de la construcción & 0.0 & 0.0 \\
Peones de transporte & 0.8 & 1.5 \\
\hline
\end{tabular}

* Profesiones en las cuales la participación de las mujeres es inferior al 25 por ciento, en el año base (1993)

Fuente: Elaboración propia sobre la base de las Encuestas del Mercado de Trabajo, FUSADES, 1993 y 1996.

Cuadro 6

Porcentaje de hombres que laboran en ocupaciones dominadas por mujeres* (1993 y 1996) (En porcentajes)

\begin{tabular}{lcc}
\hline Ocupaciones dominadas por mujeres & 1993 & 1996 \\
\hline Físicos, químicos y afines & 21 & 25.5 \\
Archiveros, bibliotecarios y afines & 12 & 55.3 \\
Profesionales de nivel medio de la salud & 24.1 & 80.6 \\
Personal de enfermería de nivel medio & 0.0 & 0.0 \\
Maestros de primaria & 25 & 39.6 \\
Maestros de enseñanza pre-escolar & 0.0 & 22.8 \\
Trabajadores y asistentes sociales de nivel medio & 0.0 & 20 \\
Secretarios y digitadores & 5.3 & 9.2 \\
Auxiliares contables y financieros & 5.7 & 57.0 \\
Empleados de servicios de información a la clientela & 24 & 11.1 \\
Personal de intendencia y de restaurantes & 16 & 42.0 \\
Otros trabajadores de servicios personales & 9.0 & 22.8 \\
Promotores & 17.8 & 9.6 \\
Operarios para fabricación de productos textiles, & & 20.2 \\
\hline productos de piel y cuero & 22.8 & 2.8 \\
\hline
\end{tabular}

* Profesiones en las cuales la participación de los hombres es inferior al 25 por ciento, en el año base (1993).

Fuente: FUSADES, Encuestas del Mercado de Trabajo, 1993 y 1997.

En términos de equidad en el acceso al mercado laboral, esta segmentación de género de las ocupaciones tiende a actuar contra las mujeres, ya que para ellas la posibilidad de elegir entre una gama de alternativas ocupacionales es más reducida que para los hombres y, por consiguiente, su rango de elección ocupacional y salarial es signifi- cativamente menor, con lo que adicionalmente se introduce una distorsión en el funcionamiento del mercado laboral.

La segregación ocupacional según sexo se presenta como un denominador común de los mercados de trabajo en la mayoría de países, indepen- 
dientemente de su nivel de desarrollo relativo: en un estudio realizado en 1992, CEPAL concluyó que en seis de doce países, cerca de la mitad de mujeres urbanas se concentraba en cinco grupos ocupacionales de las 72 a 113 profesiones y oficios existentes ${ }^{17}$.

\subsection{Indicadores de equidad en el sector infor- mal de la economía y en el sector de la microempresa}

En El Salvador, al igual que en el resto de países de América Latina, el sector informal urbano y la microempresa representan cada vez más un segmento relevante del mercado laboral, desde la perspectiva de la incorporación de la población económicamente activa. ¿En qué condiciones se insertan mujeres y hombres dentro de estos sectores cada vez más relevantes, desde la perspectiva del empleo en la economía salvadoreña? ${ }^{18}$.

Primeramente se constata que la presencia de mujeres en el sector informal y en la microempresa es mayoritaria: las mujeres representan el 65 por ciento del total de microempresarios (as) a nivel nacional y el 51 por ciento de los ocupados en el sector informal (Cuadros 7 y 8 ). Sin embargo, para hombres y mujeres es diferente el significado que tiene su participación en estos sectores. Para la abrumadora mayoría de las mujeres que se desempeñan en la microempresa, su participación en este sector no es como dirigentas o directoras de una empresa, sino más bien en calidad de autoempleadas, es decir, como ocupadas que deben generar - por su propio esfuerzo y riesgo - una remuneración mensual y, por lo general, sin contar con las regulaciones que las protejan frente a riesgos profesionales, enfermedad y/o muerte. Esta situación difiere significativamente del estatus que poseen los hombres en la microempresa, ya que ellos se desenvuelven como patronos que dirigen a trabajadores (as) remunerados o no remunerados.

De igual manera, para las mujeres empleadas en el sector informal, este segmento del mercado laboral es el más importante desde la perspectiva de las posibilidades de obtención de un empleo: el 53.7 por ciento de la población económicamente activa ocupada femenina obtiene su empleo desarrollando alguna actividad dentro del sector informal; mientras que solamente el 41 por ciento de la PEA ocupada masculina obtiene su empleo del sector informal.

\section{Cuadro 7}

Total de microempresarios por género, según categoría ocupacional (1998)

\begin{tabular}{llll}
\hline Categoría ocupacional & Total & Hombres & Mujeres \\
\hline Total & $100.00(46,8717)$ & $35.0(163,994)$ & $65.0(304,723)$ \\
Cuenta propia & 100.00 & 30.0 & 70.0 \\
Patrono & 100.00 & 61.1 & 38.9 \\
\hline
\end{tabular}

Fuentes: FOMMI II/DIGESTIC; Encuesta Microempresarial 1998.

\section{Cuadro 8}

Diferencia porcentual entre mujeres y hombres ocupados en sectores de baja productividad a nivel urbano (1996 y 1998)

\begin{tabular}{|c|c|c|c|c|c|c|}
\hline \multirow{2}{*}{ Característica } & \multicolumn{3}{|c|}{1996} & \multicolumn{3}{|c|}{1998} \\
\hline & Mujeres & Hombres & Diferencia & Mujeres & Hombres & Diferencia \\
\hline Ocupados en el SIU & 277,795 & 271,400 & $+6,395$ & 311,796 & 303,714 & $+8,082$ \\
\hline $\begin{array}{l}\text { PEA urbana ocupada } \\
\text { Ocupados SIU/PEA }\end{array}$ & 494,031 & 663,757 & $-169,726$ & 580,408 & 740,411 & $-160,003$ \\
\hline ocupada urbana & $56.2 \%$ & $40.9 \%$ & $+15.3 \%$ & $53.7 \%$ & $41.0 \%$ & $+12.7 \%$ \\
\hline
\end{tabular}

Fuente: Elaboración propia sobre la base de las Encuestas de Hogares de Propósitos Múltiples, 1996 y 1998, de la Dirección General de Estadística y Censos del Ministerio de Economía.

17. Véase CEPAL, Panorama Social de América Latina, Santiago de Chile, 1995.

18. Respecto a las diferencias conceptuales entre el sector informal y la microcmpresa, cs muy difícil cstablcccr una 
Las diferencias en el segmento productivo, al cual pertenecen las microempresas que conducen hombres y mujeres, también representan un indicador de equidad de género dentro del sector de la microempresa. Las mujeres tienen una participación mayoritaria en las empresas de subsistencia, mientras que se informa una participación relativamente más equilibrada de hombres y mujeres en las microempresas de acumulación simple y de acumulación ampliada (Cuadro 9).

Lo anterior significa que si bien las mujeres son mayoría en el sector de la microempresa, esta participación tiene lugar fundamentalmente en las unidades empresariales de menor productividad y de menor rentabilidad, las cuales - dicho sea de paso- representaron, en 1998 , el 88.4 por ciento del total de microempresas a nivel nacional. No obstante, debe reconocerse una participación más equilibrada de mujeres y hombres en los sectores de la microempresa, que presentan un mayor nivel de productividad relativa -acumulación simple y acumulación ampliada-. Es de hacer notar que estos segmentos son, precisamente, los minoritarios dentro del sector: 7.0 y 3.5 por ciento, respectivamente, en 1998.

\section{Cuadro 9 \\ Diferencia entre microempresarias y microempresarias ubicados en sectores de subsistencia (1995 y 1998) (En porcentajes)}

\begin{tabular}{lccccccc}
\hline \multicolumn{1}{c}{ Característica } & \multicolumn{3}{c}{1995} & & \multicolumn{3}{c}{1998} \\
\cline { 2 - 3 } & Mujeres & Hombres & Diferencia & & Mujeres & Hombres & Diferencia \\
\hline Subsistencia $^{1}$ & 70.2 & 28.8 & +41.4 & 67.0 & 33.0 & +30 \\
Acumulación simple $^{2}$ & 53.0 & 47.0 & +6.0 & 50.4 & 49.6 & +0.9 \\
Acumulación ampliada $^{3}$ & 25.0 & 75.0 & -50 & & 45.8 & 54.2 & -8.4 \\
\hline
\end{tabular}

Notas: ' Subsistencia: son aquellas que tienen tan baja productividad, que sólo persiguen la generación de ingresos con propósitos de consumo inmediato. En este segmento se ubican todas aquellas microempresas cuyas ventas mensuales son menores o iguales a 15000 colones; ${ }^{2}$ Acumulación simple: son aquellas microempresas en la que los recursos productivos generan ingresos que cubren los costos de la actividad, aunque sin alcanzar excedentes suficientes que permitan la inversión en crecimiento. Aquí se ubican las microempresas cuyas ventas mensuales fluctúan entre 15001 y 30000 colones; ${ }^{3}$ Acumulación ampliada: son aquellas en las que la productividad es suficientemente elevada como para permitir acumular excedente e invertirlo en el crecimiento de la microempresa. En este segmento se ubican las microempresas cuyas ventas mensuales oscilan entre 30001 y 50000 colones.

Fuente: Elaboración propia sobre la base de la información de la Encuesta Microempresarial 1995 del FOMMI I, y de la Encuesta Microempresarial de 1999 de FOMMI II/Dirección General de Estadística y Censos del Ministerio de Economía.

Esta segmentación productiva de la microempresa, que tiene también en su base discriminaciones de género, se refleja en la desigualdad en el nivel de ganancias mensuales de las empresas femeninas y de las empresas masculinas. En efecto, de acuerdo con los datos del Cuadro 10 , las microempresas propiedad de mujeres en promedio tienden a tener menores ganancias mensuales en comparación con las ganancias promedio de las microempresas de propiedad masculina, lo cual no hace más que expresar las brechas de productividad y de ingresos entre las actividades empresariales de hombres y mujeres. Así, mientras el 57.1 por ciento del total de microempresas de mujeres

separación clara entre ambos conceptos, en la medida en que muchas microcmpresas son parte dcl sector informal de la economía, y muchos auto-empleados del sector son clasificados como microempresas dentro de las estadísticas nacionales. Para efectos del presente análisis se manejarán ambos conceptos de mancra separada, pero presuponiendo la existencia de "traslapes" entre ambos sectores en la práctica. 
tienen ganancias mensuales inferiores a los 1000 colones, las microempresas de mujeres en esa misma situación son solamente el 33.5 por ciento.

No todos los factores determinantes de esta disparidad productiva entre hombres y mujeres pueden ser atribuidos a discriminaciones de género, pero en nuestra opinión los determinantes fundamentales de esta situación sí responden a una lógica de diferenciación por género: las mujeres microempresarias tienden a ubicarse en las actividades de menor rentabilidad (comercio minorista, venta ambulante, preparación de alimentos, confección de ropa, servicios personales, etc.), no solamente porque son actividades que les permiten compatibilizar sus responsabilidades familiares y del hogar con la generación de ingresos, sino porque, adicionalmente, son actividades consideradas -a nivel social y cultural- "típicamente femeninas". Además, una vez que han entrado en las actividades de menor rentabilidad, la movilidad vertical se toma extremadamente difícil para ellas: la capacitación empresarial que reciben así como los montos de crédito a los que pueden acceder son relativamente menores, en comparación con los de los hombres que se desempeñan en esas mismas actividades. Por otra parte, a nivel de las instituciones de apoyo al sector, persisten actitudes y creencias que minusvaloran la gestión empresarial de las mujeres. No es poco común el que a las microempresas de mujeres se las considere como actividades complementarias a los ingresos de la familia $y /$ o como actividades temporales y de alto riesgo, que tenderán a abandonar a medida que cese la necesidad de ingresos adicionales en la familia.

\begin{tabular}{|c|c|c|c|}
\hline \multicolumn{4}{|c|}{$\begin{array}{l}\text { Cuadro } 10 \\
\text { Porcentaje de microempresas por género, según tramo de ganancia mensua } \\
(1998)\end{array}$} \\
\hline $\begin{array}{l}\text { Ganancia } \\
\text { promedio mensual } \\
\text { (en miles de colones) }\end{array}$ & Total & Hombres & Mujeres \\
\hline Menos de 1000 & 48.9 & 33.5 & 57.1 \\
\hline 1001 a 2000 & 22.9 & 25.0 & 21.7 \\
\hline 2001 a 5000 & 21.5 & 30.0 & 16.9 \\
\hline 5001 a 10000 & 4.5 & 7.5 & 2.8 \\
\hline 10001 a 15000 & 1.2 & 2.1 & 0.7 \\
\hline 15001 a 20000 & 0.5 & 0.9 & 0.3 \\
\hline 20001 a 25000 & 0.3 & 0.6 & 0.2 \\
\hline Más de 25000 & 0.2 & 0.4 & 0.2 \\
\hline
\end{tabular}

Fuente: FOMMI II/DIGESTYC, Encuesta Microempresarial 1998.

23. Desigualdad de género en los ingresos percibidos como trabajador por cuenta propia

El término "trabajador por cuenta propia" representa una gran diversidad ocupacional, en tanto que incluye desde profesionales independientes que se desempeñan dentro del sector formal de la economía, hasta comerciantes minoristas y/o ambulantes del sector informal urbano. En términos generales, el trabajo por cuenta propia es aquel cuya remuneración no proviene de un empleador, sino que es producto de la propia gestión de una empresa o del ejercicio independiente de profesión u oficio. Lo que importa destacar es el peso relativo que esta categoría ocupacional presenta dentro del funcionamiento del mercado laboral salvadoreño, tanto a nivel del sector formal como del sector informal.

Según los datos del Cuadro 11, la proporción de mujeres y hombres en el grupo ocupacional "trabajadores por cuenta propia", ha experimentado una reducción con respecto al total de ocupados (as) en el sector urbano a nivel nacional. Esta reducción es más significativa en el caso de las mujeres -aproximadamente del 11 por ciento- respecto a la reducción en el caso de los autoempleados 
hombres -que solamente alcanzó el 1 por ciento-. Pese a este descenso en el peso relativo de los trabajadoras y de los trabajadoras por cuenta propia en relación con la población económicamente activa femenina y masculina ocupada, se ha man- tenido la mayor importancia que esta categoría ocupacional tiene para el empleo de las mujeres en la economía salvadoreña: 32 de cada 100 mujeres ocupadas en el área urbana son trabajadoras por cuenta propia.

\section{Cuadro 11}

Proporción de trabajadoras y trabajadores por cuenta propia que perciben ingresos iguales o inferiores al ingreso promedio mensual (1996 y 1998) (total del país urbano)

\begin{tabular}{|c|c|c|c|c|c|c|}
\hline \multirow[b]{2}{*}{ Característica } & \multicolumn{3}{|c|}{1996} & \multicolumn{3}{|c|}{1998} \\
\hline & Mujeres & Hombres & Diferencia & Mujeres & Hombres & Diferencia \\
\hline $\begin{array}{l}\text { Ingreso promedio } \\
\text { mensual urbano }\end{array}$ & $1,140.40$ colones & $2,071.35$ colones & & $1,422.02$ colones & $2,84.23$ colones & \\
\hline $\begin{array}{l}\text { Trabajadores } \\
\text { por cuenta propia }\end{array}$ & 193,576 & 122,430 & & 205,168 & 134,219 & \\
\hline Ocupados urbanos & 447,009 & 635,462 & & 636,662 & 743,356 & \\
\hline $\begin{array}{l}\text { Porcentaje } \\
\text { de trabajadores } \\
\text { por cuenta } \\
\text { propia /ocupados } \\
\text { urbanos }\end{array}$ & 43.3 & 19.3 & & 32.2 & 18.0 & \\
\hline $\begin{array}{l}\text { Porcentaje de } \\
\text { trabajadores por } \\
\text { cuenta propia que } \\
\text { perciben ingresos } \\
\text { iguales o menores } \\
\text { al ingreso promedio } \\
\text { mensual }\end{array}$ & 58.7 & 67.8 & -9.1 & 68.0 & 62.7 & +5.3 \\
\hline
\end{tabular}

Fuente: Elaboración propia sobre la base de las Encuestas de Hogares de Propósitos Múltiples, 1996 y 1998, Dirección General de Estadística y Censos del Ministerio de Economía.

La tendencia a reducir la importancia relativa de la categoría ocupacional "trabajador por cuenta propia" dentro de la población económicamente activa ocupada urbana, ha guardado una correlación diferente entre los hombres y las mujeres que integran esa población económicamente activa. En el caso de los hombres, esta tendencia ha estado acompañada de una disminución en el porcentaje de trabajadores por cuenta propia que devengan ingresos inferiores o iguales al salario promedio urbano, pasando del 67.8 al 62.7 por ciento, respectivamente. En el caso de las mujeres, la correlación ha sido a la inversa: del 58.7 por ciento del total de trabajadoras por cuenta propia que devengaban, en 1996, ingresos mensuales iguales o inferiores al salario mensual promedio urbano se pasó, en 1998 , al 68.0 por ciento de mujeres en esa condición. Esta tendencia expresa que las mujeres trabajadoras por cuenta propia disminuyeron en términos generales sus condiciones de remuneración mensual en ese período, en relación con una leve mejoría en las condiciones de los hombres. Esta tendencia ha estado acompañada, a su vez, de una disminución en la cobertura de la seguridad social brindada por el Instituto Salvadoreño del Seguro Social a las trabajadoras por cuenta propia. 
Cuadro 12

Cobertura de riesgos de trabajadores por cuenta propia por parte del Instituto Salvadoreño del Seguro Social, en el área urbana (1996 y 1998)

\begin{tabular}{|c|c|c|c|c|c|c|}
\hline \multirow[t]{2}{*}{ Característica } & \multicolumn{3}{|c|}{1996} & \multicolumn{3}{|c|}{1998} \\
\hline & Mujeres & Hombres & Diferencia & Mujeres & Hombres & Diferencia \\
\hline $\begin{array}{l}\text { Trabajadores } \\
\text { por cuenta propia }\end{array}$ & 193,576 & 122,430 & & 199,158 & 126,136 & \\
\hline $\begin{array}{l}\text { Cubiertos por } \\
\text { seguridad social } \\
\text { (en porcentajes) }\end{array}$ & 5.60 & 3.75 & +1.85 & 0.66 & 5.8 & -5.14 \\
\hline
\end{tabular}

Fuente: Elaboración propia sobre la base de las Encuestas de Hogares de Propósitos Múltiples 1996 y 1998, de la Dirección General de Estadística y Censos del Ministerio de Economía.

\subsection{Desigualdades en el acceso al crédito}

Desafortunadamente en nuestro país no se cuenta con información sobre la demanda y el destino del crédito a nivel nacional y sectorial de forma desagregada por género, que permita realizar un análisis global de las tendencias del acceso de hombres y mujeres a este recurso. Esta información desagregada sólo existe para el sector de la microempresa. Debido a ello, este apartado se ha construido con base en la información disponible para este sector.

\section{Cuadro 13}

Monto de crédito otorgado a mujeres propietarias de pequeñas empresas, como porcentaje del crédito otorgado a propietarios de ambos sexos de pequeñas empresas (1996)

\begin{tabular}{lc}
\hline Característica & 1996 \\
\hline Crédito hombres & $81,549,840$ colones \\
Crédito mujeres & $121,996,920$ colones \\
$\begin{array}{l}\text { Crédito total } \\
\text { Monto crédito } \\
\text { mujeres/crédito total }\end{array}$ & $203,546,790$ colones \\
\hline
\end{tabular}

Fuente: Elaboración propia sobre la base del Estudio Nacional de la Demanda de Crédito a la Microempresa, Proyecto MIP: CAM-CRS-FINCA-FOMMI-OEF-SNF, diciembre de 1996.

\section{Cuadro 14}

Monto promedio de crédito otorgado a mujeres propietarias de pequeñas empresas, dividido por el monto promedio de crédito otorgado a hombres propietarios de pequeñas empresas (1996)

\begin{tabular}{lc}
\hline Característica & 1996 \\
\hline $\begin{array}{l}\text { Monto promedio hombres } \\
\text { Monto promedio mujeres }\end{array}$ & $34,053.75$ colones \\
$\begin{array}{l}\text { Monto promedio mujeres } \\
\text { /monto promedio hombres }\end{array}$ & 38.0 \\
\hline
\end{tabular}

Fuente: Elaboración propia sobre la base del Estudio Nacional de la Demanda de Crédito a la Microempresa, Proyecto MIP: CAM-CRS-FINCA-FOMMI-OEF-SNF, diciembre de 1996.

Las diferencias en el acceso al crédito en la microempresa salvadoreña presentan rasgos particulares que es interesante analizar desde la perspectiva de género. De acuerdo con el Cuadro 14, las mujeres microempresarias recibieron la mayor proporción del monto total de crédito otorgado al sector de la microempresa en 1996: 60 por ciento del total. Sin embargo, en promedio, el monto de crédito recibido por las mujeres fue de apenas del 38 por ciento del monto promedio otorgado a los hombres. 
Cuadro 15

Demanda de crédito de microempresarios, por género (1998)

\begin{tabular}{lrcc}
\hline Monto demandado & Total & Mujeres & Hombres \\
\hline Total & 100.0 & 100.0 & 100.0 \\
Hasta 1 000 colones & 21.0 & 27.3 & 11.5 \\
1 001 a 5 000 colones & 34.3 & 39.8 & 26.1 \\
5001 a 10 000 colones & 17.0 & 16.7 & 17.4 \\
10 001 a 25 000 colones & 12.2 & 8.5 & 17.7 \\
25 001 a 50 000 colones & 7.9 & 3.5 & 14.4 \\
50 001 a 250 000 colones & 5.2 & 2.9 & 8.6 \\
Más de 250 000 colones & 1.4 & 0.4 & 3.1 \\
\hline
\end{tabular}

Fuente: Encuesta Microempresarial 1998; FOMMI II y DIGESTYC.

El acceso diferenciado de hombres y mujeres al crédito dirigido a la microempresa también tiene su explicación en factores asociados al género: las mujeres tienden a dedicarse y mantenerse en actividades de menor productividad y de menor rentabilidad, que demandan montos de créditos menores que las demandadas por las actividades de los hombres en la microempresa. De acuerdo con el Cuadro 15, en 1998 se estimó que el 67.1 por ciento de las mujeres que demandan créditos en la microempresa tienen una demanda promedio por un monto inferior a los 5000 colones, que contrasta con el menor porcentaje de hombres que demandan menos de ese monto de crédito ( 37.7 por ciento).

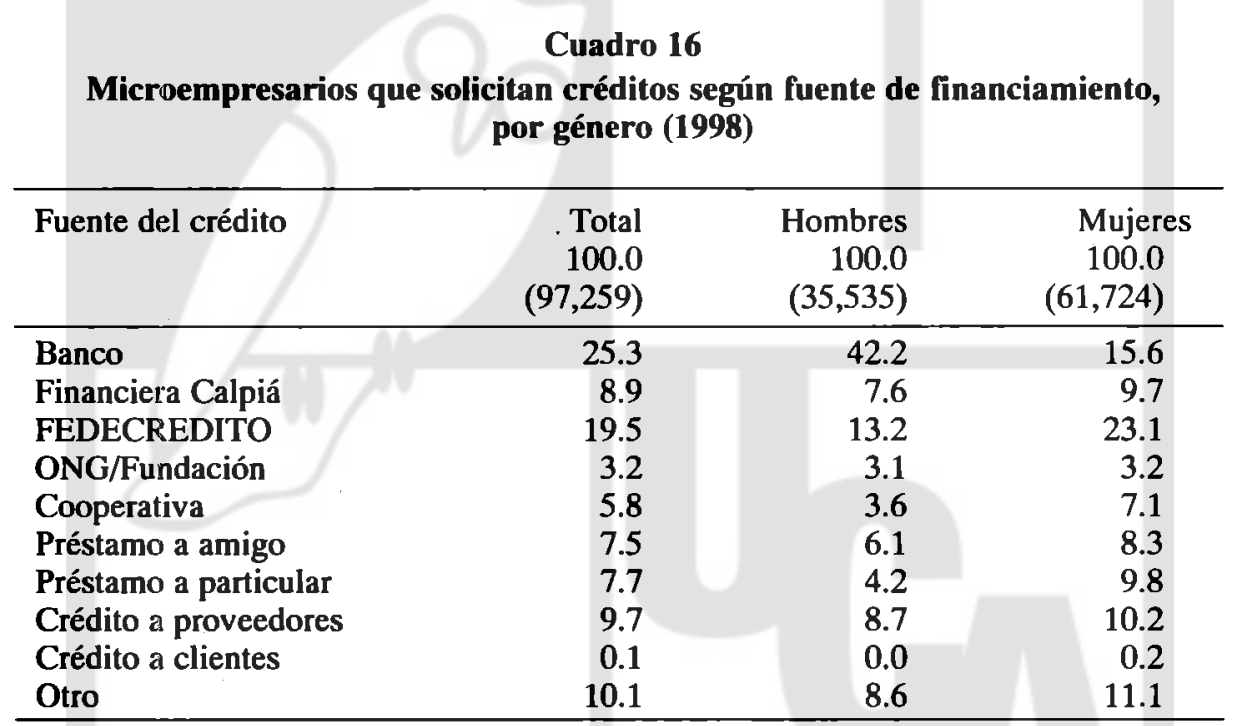

Fuente: Encuesta Microempresarial, 1998. FOMMI II/DIGESTYC.

También es importante destacar las diferencias existentes en las garantías reales que poseen hombres y mujeres - que determina la fuente de recursos financieros que satisface su demanda de créditos-con las subsecuentes diferencias en las condiciones de plazo y tasa de interés que reciben en promedio.
Según los datos del Cuadro 16, los hombres que demandan créditos representan casi la mitad de las mujeres; sin embargo, los hombres dirigen sus demandas hacia el sector bancario, mientras que las mujeres satisfacen su demanda por la vía del crédito que otorgan las denominadas "instituciones de microfinanzas" y/o por la vía del crédito 
a particulares, como se les denomina a los préstamos de los agiotistas y/o usureros(as). Esta diferencia en la fuente de financiamiento de las actividades microempresariales entre hombres y mujeres condiciona que, en promedio, los hombres tengan acceso a líneas de crédito más ventajosas en términos de montos, plazos de amortización y tasas de interés. En la base de estas diferencias se encuentran discriminaciones de género, en la medida que las mujeres tienen menos garantías reales (propiedades, fiadores asalariados, etc.) y se dedi- can a actividades de menor rentabilidad y/o de mayor riesgo en relación con los hombres.

\subsection{Diferencias en el acceso a la capacitación para el trabajo}

Las diferencias en el acceso de hombres y mujeres a la capacitación para el trabajo se refleja en los datos de los Cuadros 17 y 18. En ambos casos, se evidencia una diferencia que actúa contra las mujeres y sus posibilidades reales para mejorar su desempeño a nivel laboral, empresarial y personal.

\section{Cuadro 17}

Proporción de mujeres y hombres del sector de la microempresa capacitados (1998)

\begin{tabular}{lr}
\hline Característica & 1998 \\
\hline Mujeres capacitadas/mujeres ocupadas & $7.0 \%$ \\
Hombres capacitados/hombres ocupados & $14.0 \%$ \\
Diferencia & $-7.0 \%$ \\
\hline
\end{tabular}

Fuente: Elaboración propia sobre la base de la Encuesta Microcmpresarial 1998. Dirección General de Estadística y Censos, Ministerio de Economía, 1999.

\section{Cuadro 18}

Beneficiarios de los cursos libres de capacitación ejecutados por el Instituto Salvadoreño de Formación Profesional (INSAFORP) (1996-1998)

\begin{tabular}{|c|c|c|c|c|c|c|}
\hline & \multicolumn{2}{|c|}{1996} & \multicolumn{2}{|c|}{1997} & \multicolumn{2}{|c|}{1998} \\
\hline & Mujeres & Hombres & Mujeres & Hombres & Mujeres & Hombres \\
\hline $\begin{array}{l}\text { Capacitados } \\
\text { Porcentaje del total }\end{array}$ & $\begin{array}{l}135 \\
36.0\end{array}$ & $\begin{array}{l}245 \\
64.0\end{array}$ & $\begin{array}{l}2,005 \\
38.0\end{array}$ & $\begin{array}{l}3,272 \\
62.0\end{array}$ & $\begin{array}{l}6,294 \\
46.0\end{array}$ & $\begin{array}{l}7,389 \\
54.0\end{array}$ \\
\hline
\end{tabular}

Fuente: Instituto Salvadoreño de Formación Profesional (INSAFORP).

2.5. Diferencias en la distribución de responsabilidacles en la realización de las tareas del hogar

Un último indicador de diferencias en el funcionamiento de la economía salvadoreña nos la proporcionan las diferencias en la participación de hombres y mujeres en la realización de las tareas relacionadas con el hogar y la familia. Los resultados de este indicador (Cuadros 19 y 20) muestran una distribución desigual que actúa contra las mujeres y reproduce las condiciones de desigualdad en los diferentes ámbitos de la economía, que se han analizado en este trabajo. 


\section{Cuadro 19 \\ Proporción de microempresarios y microempresarios que realizan actividades relacionadas con el trabajo doméstico}

(1998)

\begin{tabular}{lcc}
\hline Característica & Mujeres & Hombres \\
\hline $\begin{array}{l}\text { Total de microempresarios } \\
\text { Porcentaje que se dedica únicamente } \\
\quad \text { a actividades de la empresa. }\end{array}$ & 304,722 & 163,992 \\
$\begin{array}{l}\text { Porcentaje que se dedica a labores del hogar } \\
\text { como actividad complementaria a la empresa. }\end{array}$ & 50.6 & 81.11 \\
\hline
\end{tabular}

Fuente: FOMMI II-DIGESTYC, Ministerio de Economía, Encuesta de Dinámica Microempresarial, 1998.

\section{Cuadro 20}

Tiempo semanal de trabajo que hombres y mujeres dedican a las tareas del hogar (En porcentajes)

\begin{tabular}{lcccc}
\hline & \multicolumn{4}{c}{ Tiempo que dedica a las tareas del hogar } \\
\cline { 2 - 5 } Sexo & Ninguno & Máximo 3 horas & De 4 a 7 horas & 8 horas y más \\
\hline Masculino & 23.9 & 51.6 & 16.3 & 8.3 \\
Femenino & 6.0 & 30.3 & 31.0 & 32.7 \\
\hline
\end{tabular}

Fuente: "Encuesta sobre género: consulta de opinión pública de octubre de 1999", Mujeres por la Dignidad y la Vida/Instituto Universitario de Opinión Pública de la UCA.

3. Logros y obstáculos en el cumplimientọ de los objetivos de la Plataforma de acción de Beijing, en el área mujer y economía

En términos generales, un balance general de los logros y obstáculos observados en El Salvador en el cumplimiento de los objetivos estratégicos contenidos en la Plataforma de acción de Beijing en El Salvador con respecto al área "mujer y economía", muestra una situación deficitaria, la cual deriva principalmente de la no inclusión de esta área temática dentro del contenido y de las actividades de la Política Nacional de la Mujer, que coordina actualmente el Instituto Salvadoreño para el Desarrollo de la Mujer (ISDEMU).

Esta política constituye - a juicio del gobierno y de la sociedad civil- actualmente el principal instrumento del que se dispone para garantizar el cumplimiento de los compromisos asumidos en esta conferencia. En consecuencia, al no estar considerado el tema económico dentro de las acciones que se impulsan $y / o$ se monitorean dentro de la política nacional de la mujer, los resultados en este campo quedan supeditados a los logros y las tendencias en la equidad de género, que tratan de ser modificadas a partir de otras áreas que son consideradas dentro de dicha política.

Adicionalmente y a pesar de que se informa de que hay avances en la generación de información estadística desagregada por género por parte de la Dirección General de Estadística y Censos del Ministerio de Economía, estos avances han tendido a concentrarse más en información directamente relacionada con indicadores demográficos y sociales, y menos en indicadores relevantes para el análisis económico, desde una perspectiva de género. En esta línea se inscriben los vacíos de información que todavía persisten en el cálculo del gasto público desagregado por género, en el cálculo del destino del crédito global por género y en el indicador de la contribución de las economías familiares al cálculo del producto interno bruto (PIB). Asimismo, dependencias gubernamentales e instituciones descentralizadas del Estado, como el Mi- 
nisterio de Trabajo y el Instituto Salvadoreño de Formación Profesional (INSAFORP) -dependencias en donde se genera información económica sectorial-, todavía se muestran renuentes a proporcionar de manera oportuna y ágil la información requerida para el monitoreo del estado de la equidad de género en el ámbito laboral.

A continuación se detallan -a nivel más específico- los principales avances y obstáculos que se identifican en este informe, en el área mujer y economía.

\subsection{Avances}

- Se informan avances moderados en el acceso a algunas ocupaciones dominadas por el sexo contrario, que podrían considerarse como buenos indicadores de mejoras en la equidad ocupacional. Se destacan avances en el acceso de mujeres al grupo ocupacional de "médicos", "artesanos de la madera, tejidos y cuero", "artesanos de las pieles, cueros y calzado", "operarios de líneas de ensamble", "operarios de la fabricación de productos de plástico" y "conserjes, lavadores y afines". En cuanto al acceso de hombres a ocupaciones dominadas por mujeres, se reportan avances en el grupo "archiveros, bibliotecarios y afines", "maestros de enseñanza pre-escolar", "auxiliares contables y financieros" y "personal de intendencia y restaurantes".

- Se observa un aumento en la participación de mujeres propietarias de microempresas en el segmento productivo de la reproducción ampliada; no obstante, se mantiene casi invariable su participación porcentual en los segmentos de subsistencia y de reproducción simple.

\section{2. Obstáculos}

- Con excepción de los salarios en el sector público, los salarios promedio de las mujeres y hombres continúan presentando grandes brechas contra las mujeres. Esta situación se ha tornado más preocupante desde la perspectiva de la equidad cuando, a partir de los datos oficiales disponibles, se constata que la brecha salarial entre hombres y mujeres tiende a mantenerse en los distintos niveles que conforman la escala salarial, según el grado de escolaridad alcanzada.

- A pesar de que han mejorado algunos indicadores de equidad en el acceso a ocupaciones dominadas por el sexo contrario, todavía persisten ocupaciones en las cuales la presencia de mujeres es nula o poco significativa, como por ejemplo, los grupos ocupacionales "obreros de la construcción", "pintores y limpiadores de fachadas", "mecánicos de obra de banco", "herreros y afines", "mecánicos y ajustadores de máquinas", "mecáni$\cos$ y ajustadores de equipos electrónicos", "operarios de la industria metálica", "operarios de la industria de la madera", "operarios de la producción de energía y afines", "conductores de vehículos de motor", "operarios de maquinaria o máquinas móviles" y "mensajeros, maleteros, porteros y afines".

- Se observa una tendencia hacia el incremento en el empleo de las mujeres en el sector informal de la economía, en relación con el incremento del empleo masculino en ese mismo sector.

- El porcentaje de mujeres trabajadoras por cuenta propia, que perciben ingresos mensuales inferiores al ingreso promedio mensual, se ha incrementado; mientras que el porcentaje de hombres ubicados en esa misma situación se ha reducido.

- La cobertura del Seguro Social (invalidez, maternidad, salud y muerte) ha experimentado una reducción entre las mujeres que se desempeñan como trabajadoras por cuenta propia. Esta reducción ha estado acompañada de un aumento en la cobertura de los hombres, clasificados en esa misma categoría ocupacional.

- A pesar de que las mujeres microempresarias reciben el mayor monto del crédito total destinado al sector de la microempresa, el monto promedio de créditos para las mujeres fue, en promedio, apenas un 38 por ciento del monto promedio otorgado a los hombres.

- El acceso a la capacitación para el trabajo por parte de las mujeres es menor que para los hombres.

- Las mujeres, en general, continúan teniendo una baja participación en puestos especializados y en puestos de dirección a nivel nacional: en promedio, las mujeres representaron 3 de cada 10 funcionarios y directores del sector público y privado, y 4 de cada 10 profesionales de alto nivel, científicos e intelectuales. Pero, peor aún, las mujeres vieron disminuida ligeramente su presencia en estos puestos entre 1996 y 1999.

- Finalmente, se constata la persistencia de la distribución desigual de la carga del trabajo doméstico entre mujeres y hombres, que constituye la base que permite la reproducción de las condi- 
ciones que mantienen la segregación ocupacional, salarial y productiva de las mujeres en el ámbito económico.

\subsection{La agenda pendiente}

- Unificar el movimiento de mujeres salvadoreñas en torno al cumplimiento de los compromisos y recomendaciones de Beijing y de Beijing + 5 , particularmente en el tema de "mujer y economía", sin que ello implique un abandono de las once áreas restantes de objetivos. De manera especial, el accionar del movimiento debería enfocarse hacia la inclusión del tema mujer y economía dentro de la política nacional de la mujer $y$ hacia la institucionalización del enfoque de género, en el proceso de formulación de las políticas económicas.

- Formar recurso humano calificado en el tema de mujer y economía dentro del movimiento de mujeres y dentro de las universidades e instituciones de investigación aplicada, como la mejor forma de integrar en la visión, el análisis y las propuestas en esta área las necesidades prácticas y los intereses estratégicos de las mujeres en el ámbito económico, a través de los análisis y propuestas de solución.

- Impulsar la participación de mujeres en las posiciones y los procesos de toma de decisiones sobre política económica, tanto a nivel macroeconómico como a nivel sectorial: no basta que se tengan presentes las necesidades y los intereses económicos de las mujeres al momento de definir políticas públicas, es necesario que las mujeres participen activamente en estos procesos.

- Institucionalizar un sistema nacional de información y de monitoreo de los avances de la equidad de género en la economía. La institucionalización de este sistema debería tener como una de sus pre-condiciones la implementación de reformas en el sistema de cuentas nacionales del país, para posibilitar que se genere información desa- gregada por género en variables relevantes para el análisis de las tendencias de la estabilidad y el crecimiento de la economía salvadoreña. A manera de ejemplo, se requeriría disponer de información sobre el gasto público, la contribución al producto intemo bruto y el destino del crédito desagregado por género.

- Sensibilizar a los gremios empresariales sobre la discriminación de género que sufren las mujeres empresarias en todos los niveles de productividad empresarial y, de manera particular, las mujeres de la micro, pequeña y mediana empresa. Esta sensibilización tendría como objeto incentivar - desde los gremios- la ejecución de acciones orientadas a promover una mayor participación de las mujeres en los puestos de dirigencia gremial, así como programas y/o proyectos para contribuir a la solución de necesidades prácticas y/o de los intereses estratégicos de las mujeres empresarias.

- Se requiere, asimismo, sensibilizar a los sindicatos y/o gremios profesionales sobre la importancia que la equidad de género tiene para el logro del objetivo de mejoramiento de las condiciones de desarrollo laboral y profesional de sus miembros.

Finalmente, todas las instituciones y personas involucradas y comprometidas con la igualdad y los derechos humanos de hombres y mujeres en la economía y la sociedad salvadoreña, deben replantearse los términos en los cuales ha sido abordado hasta ahora el tema de la equidad de género en nuestro país: la equidad de género es tan sólo el eslabón más hacia los objetivos de la igualdad y el "empoderamiento" de las mujeres, pero nunca puede sustituir a estos objetivos finales. En ese sentido, debe considerarse que la equidad de género debe estar acompañada de un amplio y profundo proceso de transformaciones en el ámbito de los valores, las creencias, las actitudes, los comportamientos y las instituciones dentro de la 
sociedad, que erradique definitivamente las condiciones que históricamente han hecho posible la violencia y la discriminación contra las mujeres, y que se mantienen incólumes en muchas sociedades, en las cuales se constatan avances en los indicadores de equidad de género definidos en Beijing. Tal como lo expresó Devaki Jain, en un discurso pronunciado durante la celebración de Beinjing +5 , en Nueva York:

Cambiar la condición de las mujeres, las privaciones que ellas enfrentan ya sea a través de la pobreza o por la discriminación básica requiere de cambios monumentales en las percepciones sociales de las mujeres, a lo largo de las castas, clases, etnias y otras diferencias. Los estudios están demostrando que al poseer propiedades, contar con ingresos, tener educación, incluso teniendo igualdad en los indicadores sociales, como la cercanía a uno de los GDI o GEM, como Kerala en India, no han reducido ni la violencia contra las mujeres o las tasas de dote ni la situación básica que hace que un hombre adulto o adolescente viole a una niña, aún si ella es su pariente o vecina... estamos encontrando que la igualdad de género, que ha sido dada como el propósito de esta conferencia, es una condición necesaria pero no suficiente para la emancipación de las mujeres, no es una condición suficiente para eliminar la discriminación y opresión de los sẹctores socialmente excluidos de la sociedad ${ }^{19}$.

\section{Bibliografía}

CEPAL. "Indicadores de género para el seguimiento y la evaluación del Programa de Acción Regional para las mujeres de América Latina y el Caribe, 19952001, y la Plataforma de Acción de Bcijing". Santiago de Chile, 1999.

Dirección General de Estadística y Ccnsos-Programa de Fomento a la microempresa en Zonas Marginales de la Unión Europea (FOMMI II). Encucsta Microcmpresarial 1998. San Salvador, octubre, 1998.

Dirección General de Estadística y Censos. Encucsta dc Hogares de Propósitos Múltiples, 1996, 1997 y 1998. Ministerio de Economía de la República de El Salvador.

Fundación Salvadoreña para el Desarrollo Económico y Social (FUSADES). Encuestas sobre el mercado de trabajo, 1993 y 1996/1997. Departamento de Estudios Económicos y Sociales, San Salvador.

García, Ana Isabel (cd.). "La situación de las mujeres en Centroamérica: una evaluación en el umbral del siglo XXI". Programa Conjunto del Diálogo Interamericano y del Centro Internacional de Investigación de la Mujer (ICRW). Fundación Géncro y Sociedad. San José, Costa Rica, 1999.

Las Dignas/IUDOP. Encucsta sobre género. Consulta de opinión pública de octubre de 1999. San Salvador, 1999.

Programa de Fomento a la Microempresa de Zonas Marginales de la Unión Europea (FOMMI I). Encuesta de la microempresa salvadoreña. San Salvador, julio, 1995.

Proyecto de Innovaciones para la Microempresa (CAMCRS-FINCA-FOMMI-OEF-SNF). Estudio Nacional sobre la Demanda de Créditos a la microempresa, diciembre, 1996.

19. Centro de la Mujer Peruana Flora Tristán, Boletín Informativo No. 36 . 